\title{
Allografts in joint reconstruction: ESSKA making a difference
}

\author{
Tim Spalding ${ }^{1}\left[\begin{array}{l}D \\ \text { Peter Verdonk }\end{array}{ }^{2} \cdot\right.$ Laura de Girolamo $^{3} \cdot$ Romain Seil $^{4} \cdot$ David Dejour $^{5}$
}

Received: 16 April 2019 / Accepted: 23 April 2019 / Published online: 10 May 2019

(c) European Society of Sports Traumatology, Knee Surgery, Arthroscopy (ESSKA) 2019

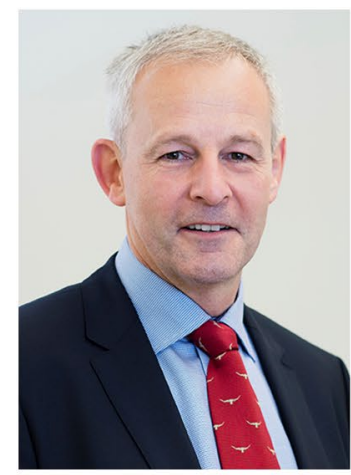

Tim Spalding

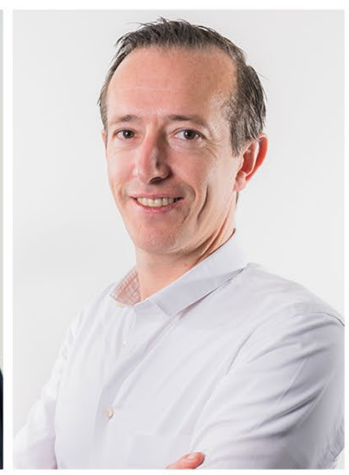

Peter Verdonk

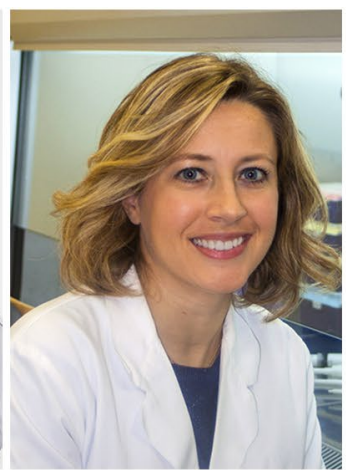

Laura de Girolamo

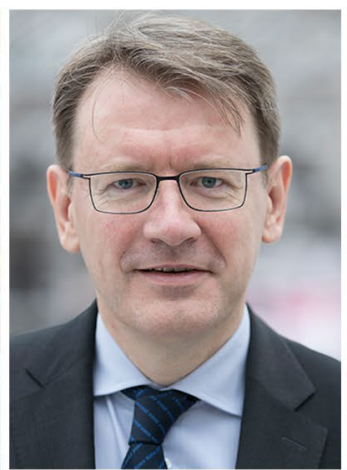

Romain Seil

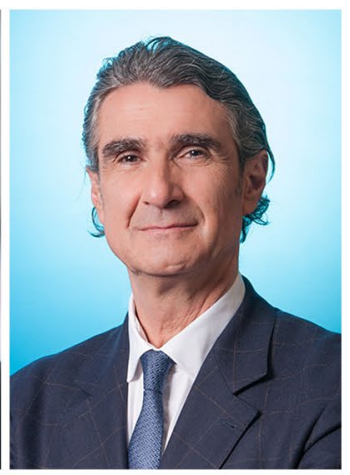

David Dejour
Recycling human tissue for the benefit of reconstructing injured joints is an appealing option, using healthy fully developed tissue to replace damaged areas. From pioneering work over 30 years ago clinical results now give surgeons the confidence that allograft tissue is both a viable option and a successful solution. Naturally, use must be balanced against risks, and the appeal of ready-made tissue may be outweighed by lack of success, failure due to processing issues or making a patient worse off by complications of infection.

This special issue represents the first phase of the ESSKA European Allograft Initiative, the work of Arthroscopy, Cartilage and Basic Science Committees within ESSKA,

Tim Spalding

Tim.spalding@uhcw.nhs.uk

1 University Hospitals Coventry and Warwickshire NHS Trust, Clifford Bridge Road, Coventry CV2 2DX, UK

2 Antwerp Orthopaedic Center, Antwerp, Belgium

3 Othopaedic Biotechnology Laboratory, IRCCS Orthopaedic Institute Galeazzi, Milan, Italy

4 Department of Orthopaedic Surgery, Clinique d'Eich-Centre Hospitalier de Luxembourg, Luxembourg, Luxembourg

5 Department of Knee Surgery, Lyon Ortho Clinic, Lyon, France collaborating to tackle head on the availability, awareness and cost-effectiveness of allograft tissue in joint reconstruction in Europe. Surgeons may recognise the need for allograft tissue but a previous ICRS focus meeting in 2016 demonstrated the heterogeneity reported among the European countries in terms of availability, types of allograft, indications, and costs. The allograft initiative project provides awareness within our scientific community so we can recommend shared and science-based options for treatment.

The papers published in this Special Issue are important, providing both an in-depth analysis of a specific treatment option and a demonstration of what is possible through collaboration across countries and disciplines.

\section{Economic data on allografts}

Allograft technologies might be more expensive, and their sustainability needs to be justified in the world of rationing healthcare. Each country in Europe and worldwide will have their own level of value for a treatment but the cornerstone for any approval to use such clinically valuable treatments is accurate cost-effectiveness information, and this is the basis of the initiative. The cost-effectiveness Health Technology Appraisal (HTA) was funded through the ESSKA Foundation. 
To put this together Professor Waugh and his team from Effective Evidence and Warwick Evidence in UK compiled an extensive HTA report which will be published in full on the ESSKA website. For this issue the analysis is broken down into four succinct papers $[7,8,12,13]$. The full version makes for an educational read, reflecting on the true values of what we spend and save, accounting for the permutations of treatments, the 'treatment model' that is required for the computations. Costs of treatments saved, physiotherapy input and any potential delay to knee replacement are included. In this issue the modelling is applied to each of the clinical treatment questions and the key elements of methodology in evaluating cost-effectiveness is detailed in the 'primer' report by Professor Waugh [14]. Strict requirements for health impact outcome measures (EQ-5D) are emphasised along with accurate and complete data collection, while knowing what would be likely to happen without treatment.

\section{Basic science behind allografts}

Clinical results depend on understanding the basic science of allografts, and the biology of integration and the mechanical properties of allografts are analysed in two papers $[2,9]$. It emerges that there is coordination of cell types, growth factors and cytokines in the early inflammatory and subsequent remodelling phases. Designing strategies to improve integration and survival of the allograft implants depend on gaining understanding of the complex biological events at the host-implant interface. Mechanically, tendon allografts are more vulnerable to overstretching in the phase of degradation compared to autografts, and this is due to a longer revascularization process that also starts later; that science under pins the clinical implication that grafts chosen should tolerate high loads and that rehabilitation programs should take into account the longer time period required for full integration and maturation.

\section{Clinical data}

\section{Allograft ligament reconstruction}

The clinical outcomes and use of allograft tendons for soft tissue ligament reconstruction have been evaluated in clinical reviews covering primary ACL reconstruction, revision ACL reconstruction and multi ligament injuries $[1,6,11]$. Allografts have a strong appeal, reducing operation time and morbidity from graft harvest, but historically, results have been recognised to be inferior when using irradiated grafts. The current review on primary ACL reconstruction [6] details the clinical results of use of non-irradiated sterilised graft tissue and how allografts are a suitable option for the older patients taking into account slower integration and the influence of chemical processing techniques, providing a handy guide for surgeons on decision making. Caution still remains for use of allografts in the younger patient. Such patients tend to be more active and there is increasing understanding of the higher risks in this age group. The evidence is weak but allografts in the young are likely to carry increased risk of failure. This is an area for further comparative work. In PCL reconstruction and multiligament reconstruction the clinical results of using allograft tissue appear equal based on the current available data [1, 11], and therefore, the choice for using allografts is based on preference and cost, while of course taking into account the longer maturation of allografts. Naturally, therefore, pure cost-effectiveness analysis is not showing use of allografts in ligament surgery to be favourable. Graft availability and donor-site morbidity become the dominant factor in decision making in these clinical situations.

\section{Osteochondral allografts}

Cost-effectiveness for osteochondral allograft transplantation (OCA) is very high [8] with the cost per quality-adjusted life year (QALY) much lower than many other treatments considered for chondral and osteochondral repair. Initial costs are higher - and, therefore, off-putting to funders-but the excellent long-term survival translates into a much high degree of cost-effectiveness! Surgeons and funders need to take on board the value of such analysis when considering treatments that appear expensive at first sight but can result in very satisfactory outcomes [5].

\section{Meniscal allografts}

The clinical review of meniscus allograft transplantation (MAT) and the cost-effectiveness analysis clearly show the high degree of clinical effectiveness of MAT with a long history [13]. Control data are, however, lacking on what happens to the patients who have symptoms after loss of meniscus but who do not get MAT. Not every patient develops early onset of intrusive symptoms after meniscectomy-we know the long-term risk of OA after meniscectomy overall but not just in the cohort of approximately $20 \%$ with early onset symptoms [4]. This is an important area for further analysis. There is only one comparative randomised study on effectiveness available, designed as a pilot, indicating the complexity of designing randomised controlled studies in this area [10]. It points towards a benefit, but longer-term data with more numbers are required, along with all the relevant costs of treatment.

The influence of associated chondral damage is also a confounding factor in MAT, with clinical reviews indicating 
a higher failure rate yet equal magnitude of gain in clinical scores where the graft survives. As is pointed out, it is possible that MAT may be both less successful and more costeffective in the more severe group because they have more to gain [13]. Detailed QOL scores that can be converted to a utility measure, such as WOMAC or SF-12, to allow costs per quality-adjusted life year (QALY) need to be obtained. Without treatment there may be some natural recovery, or patients may simply reduce activity and learn to live with the problem. Non-MAT interventions such as intensive physiotherapy or injectable biologics need evaluation in the postmeniscectomy pathway.

\section{What is next?}

Allografts are an important treatment option that should be available to every patient. The barrier of cost has to be balanced against the gains - the basis of cost-effectiveness analysis. Scarcity of allograft tissue throughout the European community is obvious. Patients do not have allograft tissues available while superior outcome and cost-effectiveness have been proven. Improvement is required in the provision of allografts from European Tissue banks and for too long supply and quality has been arguably low.

We hope that the readers will find useful information in this Special Issue to address their choice, not only for knee surgery but also for other regions such as foot and ankle [3] and will follow the next steps of the initiative which include development of consensus statements by the steering group and assessment by a larger rating group. The result will be specific statements and recommendations about the use of allografts in clinical situations at European level, that can be further agreed by representative surgeons and societies around the world.

We believe that consensus and clinical data along with cost-effectiveness will be powerful and each ESSKA member should be proud of the collaborative effort in achieving change. Indeed, the collaboration between the members of ESSKA reflects the drive to make change for the good of our patients. The barriers to using specific allografts for specific indications remain too high but we think we now have the data to answer those critics who have demanded the information for decision making.

\section{References}

1. Condello V, Zdanowicz U, Di Matteo B, Spalding T, Gelber PE, Adravanti P, Heuberer P, Dimmen S, Sonnery-Cottet B, Hulet C, Bonomo M, Kon E (2018) Allograft tendons are a safe and effective option for revision ACL reconstruction: a clinical review. Knee Surg Sports Traumatol Arthrosc. https://doi.org/10.1007/ s00167-018-5147-4
2. de Girolamo L, Ragni E, Cucchiarini M, van Bergen CJA, Hunziker EB, Chubinskaya S (2018) Cells, soluble factors and matrix harmonically play the concert of allograft integration. Knee Surg Sports Traumatol Arthrosc. https://doi.org/10.1007/s0016 7-018-5182-1

3. Diniz P, Pacheco J, Flora M, Quintero D, Stufkens S, Kerkhoffs G, Batista J, Karlsson J, Pereira H (2019) Clinical applications of allografts in foot and ankle surgery. Knee Surg Sports Traumatol Arthrosc. https://doi.org/10.1007/s00167-019-05362-0

4. Drobnič M, Ercin E, Gamelas J, Papacostas ET, Slynarski K, Zdanowicz U, Spalding T, Verdonk P (2019) Treatment options for the symptomatic post-meniscectomy knee. Knee Surg Sports Traumatol Arthrosc. https://doi.org/10.1007/s00167-019-05424-3

5. Filardo G, Andriolo L, Soler F, Berruto M, Ferrua P, Verdonk P, Rongieras F, Crawford DC (2018) Treatment of unstable knee osteochondritis dissecans in the young adult: results and limitations of surgical strategies - the advantages of allografts to address an osteochondral challenge. Knee Surg Sports Traumatol Arthrosc. https://doi.org/10.1007/s00167-018-5316-5

6. Hulet C, Sonnery-Cottet B, Stevenson C, Samuelsson K, Laver L, Zdanowicz U, Stufkens S, Curado J, Verdonk P, Spalding T (2019) The use of allograft tendons in primary ACL reconstruction. Knee Surg Sports Traumatol Arthrosc. https://doi.org/10.1007/s0016 7-019-05440-3

7. Mistry H, Metcalfe A, Colquitt J, Loveman E, Smith NA, Royle P, Waugh N (2019) Autograft or allograft for reconstruction of anterior cruciate ligament: a health economics perspective. Knee Surg Sports Traumatol Arthrosc. https://doi.org/10.1007/s00167-019-05436-Z

8. Mistry H, Metcalfe A, Smith N, Loveman E, Colquitt J, Royle P, Waugh N (2019) The cost-effectiveness of osteochondral allograft transplantation in the knee. Knee Surg Sports Traumatol Arthrosc. https://doi.org/10.1007/s00167-019-05392-8

9. Seitz AM, Dürselen L (2018) Biomechanical considerations are crucial for the success of tendon and meniscus allograft integration-a systematic review. Knee Surg Sports Traumatol Arthrosc. https://doi.org/10.1007/s00167-018-5185-y

10. Smith NA, Parsons N, Wright D, Hutchinson C, Metcalfe A, Thompson P, Costa ML, Spalding T (2018) A pilot randomized trial of meniscal allograft transplantation versus personalized physiotherapy for patients with a symptomatic meniscal deficient knee compartment. Bone Joint J. https://doi.org/10.1302/0301620x.100b1.bjj-2017-0918.r1

11. Strauss MJ, Varatojo R, Boutefnouchet T, Condello V, Samuelsson K, Gelber PE, Adravanti P, Laver L, Dimmen S, Eriksson K, Verdonk P, Spalding T (2019) The use of allograft tissue in posterior cruciate, collateral and multi-ligament knee reconstruction. Knee Surg Sports Traumatol Arthrosc. https://doi.org/10.1007/s0016 7-019-05426-1

12. Waugh N, Mistry H, Metcalfe A, Colquitt J, Loveman E, Royle P, Smith NA (2019) Allografts in reconstruction of the posterior cruciate ligament: a health economics perspective. Knee Surg Sports Traumatol Arthrosc. https://doi.org/10.1007/s00167-019-05477-4

13. Waugh N, Mistry H, Metcalfe A, Loveman E, Colquitt J, Royle P, Smith NA, Spalding T (2019) Meniscal allograft transplantation after meniscectomy: clinical effectiveness and cost-effectiveness. Knee Surg Sports Traumatol Arthrosc. https://doi.org/10.1007/ s00167-019-05504-4

14. Waugh N, Mistry H (2019) A brief introduction to health economics. Knee Surg Sports Traumatol Arthrosc. https://doi. org/10.1007/s00167-019-05372-y

Publisher's Note Springer Nature remains neutral with regard to jurisdictional claims in published maps and institutional affiliations. 